\title{
Synthesis, characterization, and antioxidant activity in vitro of selenium-Euryale ferox Salisb. polysaccharide
}

\author{
Fang Dong ${ }^{1,2^{*}+} @$, Hu-Zhe Zheng ${ }^{1,3+}{ }^{+}$Woo-Sik Jeong ${ }^{3}$, Shin-Kyo Chung ${ }^{3}$, Zhong-Yuan Qu ${ }^{2}$, Xiang Zou ${ }^{2,4}$, \\ Chen Liu ${ }^{5}$, Qiong Xiang ${ }^{1}$ and Feng Feng ${ }^{1 *}$
}

\begin{abstract}
In order to obtain and explore selenide composed of selenium and polysaccharide, three parameters were selected to optimize the synthesis process of selenium-Euryale ferox Salisb. polysaccharide (Se-ESPS) by Box-Behnken design. Furthermore, ESPS-B1 separated from ESPS was selenitized to Se-ESPS-B1 by the optimal synthesis process, then the characterization, and antioxidant activity in vitro of Se-ESPS-B1 were explored. The result manifested that the Se content of Se-ESPS was $(2.915 \pm 0.03) \mathrm{mg} / \mathrm{g}$ according to the optimal synthesis process of Se-ESPS (reaction time at $5 \mathrm{~h}$, reaction temperature at $81{ }^{\circ} \mathrm{C}$, weight ratio of $\mathrm{Na}_{2} \mathrm{SeO}_{3}$ to $\mathrm{ESPS}$ at $0.9 \mathrm{~g} / \mathrm{g}$ ). A series of detection results indicated that the characterizations of Se-ESPS-B1 were apparently distinguished from that of ESPS-B1. Moreover, the antioxidant experiments in vitro demonstrated that Se-ESPS-B1 could exert antioxidant activity by scavenging DPPH, $A B T S, O H$, and increasing reduction ability. In conclusion, the synthesis process is an effective approach to harvest seleniumpolysaccharide, and Se-ESPS-B1 may be utilized as a potential antioxidant or selenium nutritional supplement.
\end{abstract}

Keywords: Selenium-Euryale ferox Salisb. polysaccharide, Synthesis optimization, Characterization, Antioxidant activity

\section{Introduction}

Oxidative stress and peroxidation are regarded as the critical causes of various physical problems $[1,2]$. As an essential trace element, selenium has been proved to have a wide range of biological activities, especially in antioxidation [3,4]. Selenium compounds and selenium enzymes are scavengers of reactive oxygen species (ROS). In chemical experiments, selenium has been found to trap electrophilic ROS [5]. Besides, selenium plays an antioxidant role in human body mainly through selenium enzymes, such as glutathione peroxidase (GPx) and thioredoxin oxidoreductase (TrxR) [6]. GPx with

*Correspondence: dong1234fang@126.com; 20171018@jsfpc.edu.cn ${ }^{\dagger}$ Fang Dong and Hu-Zhe Zheng contributed equally to this work

${ }^{1}$ School of Health Sciences, Jiangsu Food and Pharmaceutical Science

College, Huai'an 223003, China

Full list of author information is available at the end of the article selenocysteine as the active center can catalyze the conversion of reduced glutathione to oxidized glutathione and reduce toxic peroxides to non-toxic hydroxyl compounds [7]. TrxR, which has a unique but essential selenocysteine residue in its $\mathrm{C}$-terminal redox center, can regulate redox reaction, reduce the transcription of proinflammatory factors in mitochondria, alleviate oxidative stress, reduce mitochondrial apoptosis and reduce inflammatory response [8-10].

Selenium deficiency in the diet can gradually lead to some diseases, such as Kachin-Beck disease and Keshan disease $[11,12]$. Moreover, selenium is a rare and dispersed element, which is mainly in the inorganic form. However, the therapeutic dosage of inorganic selenium is close to the toxic dosage, and the direct absorbability of inorganic selenium has the great safety risks [13].

Euryale ferox Salisb. is cultivated in the pool and marsh of southern China, and its kernel is utilized as common 
food and traditional Chinese medicine for benefitting the body and treating chronic diseases such as diabetes and nephritis by reducing the body's peroxidation level [14]. The evidences show that the important reason for the biological activity of the kernel of Euryale ferox Salisb. is that it contains considerable active polymers, namely polysaccharides $[15,16]$.

The combination of inorganic selenium with polysaccharide is considered to be more bioactive and safer for humans [17]. Besides, it is believed that the biological safety and activity of the physical mixture of inorganic selenium and polysaccharide is lower than that of selenium-polysaccharide due to the conversion of inorganic selenium to organic selenium [18]. Unfortunately, the natural selenium-polysaccharide is scarce in nature. To efficiently harvest selenium-polysaccharide, continuous attention has been paid to the chemical synthesis of selenium-polysaccharide [19-21]. Compared with that of polysaccharide, the microstructure of selenium-polysaccharide may be changed. Furthermore, it is a consensus that the activity of polysaccharide and its microstructure are strongly linked [22-24].

Therefore, we engaged Box-Behnken design (BBD) to optimize the synthesis of selenium-Euryale ferox Salisb. polysaccharide (Se-ESPS) and explored the variations on the characterization and antioxidant activity in vitro.

\section{Materials and methods Sample material}

The kernels of Euryale ferox Salisb., were collected from Hung-tse Lake in Huai'an, Jiangsu Province, China, and stored at room temperature after drying in air.

\section{Extraction, purification, and isolation of ESPS}

The dried kernels of Euryale ferox Salisb. were reflux treated by $\mathrm{n}$-hexane for $1 \mathrm{~h}, 3$ cycles to remove nonpolar impurities. Then, the treated kernels were extracted by the water reflux method. The protein of the water extract was removed by Sevag solution and the pigment was removed by macroporous resin D301R. After that, the absolute alcohol was added into the water extract with protein and pigment removed until the final volume of ethanol was $90 \%$. Twenty four hours later, the polysaccharide was centrifuged and collected, named ESPS. Further, ESPS was isolated by DEAE- 52 cellulose column and SephadexG-150 with $0.05 \mathrm{~mol} / \mathrm{L} \mathrm{NaCl}$ solution. The eluent was dialyzed to $\mathrm{Cl}^{-}$free by distilled water, and then freeze-dried to harvest the high-purity polysaccharide, named ESPS-B1. In this paper, ESPS was used in the selenization optimization process and Se-ESPS-B1 was used in analysis of the characterization and antioxidant activity in vitro.

\section{Selenization process}

ESPS and $\mathrm{Na}_{2} \mathrm{SeO}_{3}$ in a certain proportion were put in the Erlenmeyer flask with $200 \mathrm{~mL} 0.05 \% \mathrm{HNO}_{3}$ solution. Immediately, the mixed solution sealed in the Erlenmeyer flask was reacted at the stated time and temperature in water bath oscillator. After adjusting its $\mathrm{pH}$ value of 5-6 with $\mathrm{Na}_{2} \mathrm{CO}_{3}$, the solution that had completed the selenization reaction was dialyzed by dialysis bag $\left(\mathrm{M}_{\mathrm{w}}\right.$ cut-off: $8 \times 10^{3}-14 \times 10^{3}$ ) with tap water for $72 \mathrm{~h}$ and purified water for $24 \mathrm{~h}$ [18]. When dialysis solution did not present red color after the addition of ascorbic acid, indicating that there was no free $\mathrm{SeO}_{3}{ }^{2-}$, the Se-ESPS solution was freeze-dried.

\section{Single-factor design of Se-ESPS}

Reaction time (3, 4, 5, 6, $7 \mathrm{~h}$ ), reaction temperature (50, $60,70,80,90{ }^{\circ} \mathrm{C}$ ), and weight ratio of $\mathrm{Na}_{2} \mathrm{SeO}_{3}$ to ESPS $(0.2,0.4,0.6,0.8,1.0 \mathrm{~g} / \mathrm{g})$ were investigated as the independent variables in the single-factor experiments. The Se content as dependent variable was gotten on the basis of the linear regression equation $\left(\mathrm{Y}=105.8 \mathrm{X}+2.9, \mathrm{R}^{2}=\right.$ 0.9999) of selenium standard solution (National standard sample No. GSB 04-1751-2004, Beijing General Research Institute of Nonferrous Metals, China), which was measured at $196.026 \mathrm{~nm}$ by Varian710-ES ICP-OES (Varian Inc., USA).

\section{Box-Behnken design of Se-ESPS}

In the light of the results of single factor investigation, three levels were selected from the three factors, shown in Table 1. Box-Behnken design was used to carry out response surface optimization by Design-Expert 7.0 software (Stat-Ease, USA) [25-27].

\section{Appearance observation}

Se-ESPS-B1 and ESPS-B1 were placed on the white paper. The color, morphology and other appearance were observed under sunlight.

\section{Infrared spectroscopy}

1-2 mg Se-ESPS-B1 and ESPS-B1 were merged with 100-200 mg KBr respectively. The infrared spectra of samples were measured at the $4000-500 \mathrm{~cm}^{-1}$ byNicolet380 FTIR (Thermo Fisher Scientific, USA).

Table 1 Codes schedule of variables using BBD

\begin{tabular}{llll}
\hline Variables & \multicolumn{3}{l}{ Code and level } \\
\cline { 2 - 4 } & $\mathbf{- 1}$ & $\mathbf{0}$ & $+\mathbf{1}$ \\
\hline $\mathrm{X}_{1}$, reaction time $(\mathrm{h})$ & 4 & 5 & 6 \\
$\mathrm{X}_{2}$, reaction temperature $\left({ }^{\circ} \mathrm{C}\right)$ & 70 & 80 & 90 \\
$\mathrm{X}_{3}$, mass ratio of $\mathrm{Na}_{2} \mathrm{SeO}_{3}$ to ESPS $(\mathrm{g} / \mathrm{g})$ & 0.6 & 0.8 & 1.0 \\
\hline
\end{tabular}




\section{Thermogravimetric detection}

Se-ESPS-B1 and ESPS-B1 were detected by TGA2 thermogravimetric analyzer (METTLER TOLEDO International Co., Ltd., Switzerland). Detection Parameters: air flow rate $50 \mathrm{~mL} / \mathrm{min}$, heating rate $10{ }^{\circ} \mathrm{C} / \mathrm{min}$, temperature range $30-800{ }^{\circ} \mathrm{C}$.

\section{$X$-ray diffraction detection}

Se-ESPS-B1 and ESPS-B1 were determined by D8AdvanceX-ray diffractometer (Bruker Corporation, Germany). (Detection Parameters: $2 \theta=5^{\circ}-80^{\circ}$, room temperature).

\section{$\mathrm{X}$-ray photoelectron spectroscopy detection}

The dried and fully ground Se-ESPS-B1 and ESPS$\mathrm{B} 1$ were detected by the K-alpha X-ray photoelectron spectrometer (Thermo Fisher Scientific, USA). Detection parameters: sample thickness less than $5 \mathrm{~mm}$, cone-shaped double anode $\mathrm{Mg} \mathrm{K \alpha}$ rays, $12 \mathrm{kV}, 180 \mathrm{~W}$, background vacuum $1 \times 10^{-6} \mathrm{~Pa}$ in the analysis room, contaminated $\mathrm{C} 1 \mathrm{~s}(\mathrm{Be}=284.6 \mathrm{eV})$ used for charge correction.

\section{Scanning electron microscope observation}

After being sprayed with Au, Se-ESPS-B1 and ESPS-B1 were observed by FEG450 scanning electron microscope (FEI Company, USA).

\section{DPPH radical scavenging capacity}

$1 \mathrm{~mL}$ Se-ESPS-B1 with different concentrations (0.2, $0.4,0.6,0.8,1.0 \mathrm{mg} / \mathrm{mL}$ ) were merged with $1 \mathrm{~mL}$ $0.5 \mathrm{mmol} / \mathrm{mL}$ DPPH solution and $10 \mathrm{~mL} 60 \%$ ethanol respectively. After standing at normal atmospheric temperature and away from light for $0.5 \mathrm{~h}$, the absorbance was determined at $517 \mathrm{~nm}$ by UV-5200 UV-Vis spectrophotometer (Shanghai Metash Instrument Co., Ltd., China) [28]. The operating procedures of ascorbic acid and ESPS-B1 were the same as that of Se-ESPS-B1. The calculation formula was shown as follows:

$$
X=\left[\frac{A_{0}-\left(A_{i}-A_{j}\right)}{A_{0}}\right] \times 100 \%
$$

In formula $1, \mathrm{X}$ is DPPH radical scavenging rate; $\mathrm{A}_{0}$ is the absorbance value of sample blank control group. $A_{i}$ is the absorbance value of the sample group; $A_{j}$ is the absorbance value of the DPPH blank control group.

\section{ABTS radical scavenging capacity}

$1 \mathrm{~mL}$ Se-ESPS-B1 with different concentrations $(0.2$, $0.4,0.6,0.8,1.0 \mathrm{mg} / \mathrm{mL}$ ) were merged with $6 \mathrm{~mL}$ ABTS working solution which was obtained from ABTS stock solution prepared by equal volume of $7.4 \mathrm{mmol} /$ $\mathrm{mL}$ ABTS solution and $2.6 \mathrm{mmol} / \mathrm{mL} \mathrm{K}_{2} \mathrm{~S}_{2} \mathrm{O}_{8}$ solution. After avoiding light at normal temperature for $6 \mathrm{~min}$, the absorbance was determined at $734 \mathrm{~nm}$ by UV-5200 UV-Vis spectrophotometer [29]. The operating procedures of ascorbic acid and ESPS-B1 were the same as that of Se-ESPS-B1. The calculation formula was the same as formula 1. $\mathrm{X}$ is ABTS radical scavenging rate; $A_{0}$ is the absorbance value of the sample blank control group. $A_{i}$ is the absorbance value of the sample group; $A_{j}$ is the absorbance value of the ABTS blank control group.

\section{OH radical scavenging capacity}

$1 \mathrm{~mL}$ Se-ESPS-B1 with different concentrations $(0.2,0.4$, $0.6,0.8,1.0 \mathrm{mg} / \mathrm{mL}$ ) were merged with $2 \mathrm{~mL} 5 \mathrm{mmol} /$ $\mathrm{mL} \mathrm{FeSO}_{4}$ solution, $2 \mathrm{~mL}$ distilled water $2 \mathrm{~mL} 5 \mathrm{mmol} /$ $\mathrm{mL}$ salicylic acid ethanol solution and $2 \mathrm{~mL} 5 \mathrm{mmol} / \mathrm{mL}$ $\mathrm{H}_{2} \mathrm{O}_{2}$ solution. 30 min later, the absorbance was detected at $510 \mathrm{~nm}$ by UV-5200 UV-Vis spectrophotometer [30]. The operating procedures of ascorbic acid and ESPS-B1 were the same as that of Se-ESPS-B1. The calculation formula was the same as formula $1 . \mathrm{X}$ is $\cdot \mathrm{OH}$ radical scavenging rate; $A_{0}$ is the absorbance value of the sample blank control group. $A_{i}$ is the absorbance value of the sample group; $A_{j}$ is the absorbance value of the $\mathrm{H}_{2} \mathrm{O}_{2}$ blank control group.

\section{Total reduction capacity}

$1 \mathrm{~mL}$ Se-ESPS-B1 with different concentrations $(0.2,0.4$, $0.6,0.8,1.0 \mathrm{mg} / \mathrm{mL}$ ) were merged with $1 \mathrm{~mL} 1 \%(\mathrm{w} / \mathrm{v})$ $\mathrm{K}_{3}\left[\mathrm{Fe}(\mathrm{CN})_{6}\right]$ and $1 \mathrm{~mL}$ PBS $(\mathrm{pH}=6.6)$. After $20 \mathrm{~min}$ reaction at $50{ }^{\circ} \mathrm{C}$, the reaction solution was added with $2 \mathrm{~mL} 0.3 \%$ trichloroacetic acid. Then, $2 \mathrm{~mL}$ mixed solution added with $2 \mathrm{~mL}$ distilled water and $0.4 \mathrm{~mL} 0.3 \%$ (w/v) $\mathrm{FeCl}_{3}$ was reacted at $50{ }^{\circ} \mathrm{C}$ for $10 \mathrm{~min}$ [31]. The absorbance was detected at $700 \mathrm{~nm}$ by UV-5200 UV-Vis spectrophotometer. The operating procedures of ascorbic acid and ESPS-B1 were the same as that of Se-ESPS-B1. The calculation formula was shown as follows:

$$
X=A_{1}-A_{2}
$$

In formula $2, \mathrm{X}$ is the reduction capacity; $\mathrm{A}_{1}$ is the absorbance value of the sample group; $A_{2}$ is the absorbance value of the blank group.

\section{Statistical analysis}

The experiments were executed in triplicate, and the results were presented as $\bar{x} \pm s$. Values were evaluated by analysis of variance (ANOVA). 

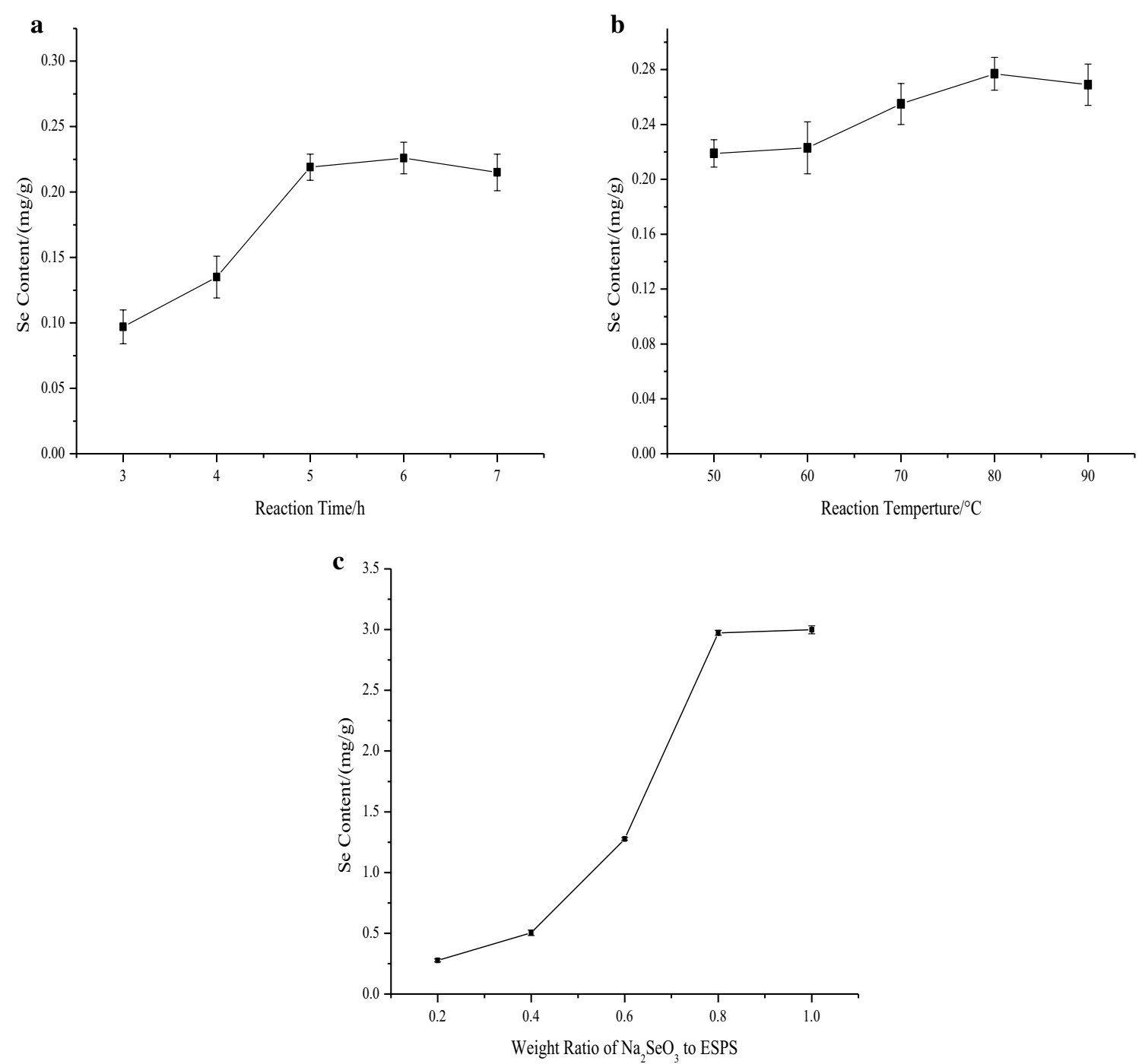

Fig. 1 Effects of different factors on Se-ESPS synthesis. a Fixed conditions: reaction temperature $50{ }^{\circ} \mathrm{C}$, weight ratio of $\mathrm{Na}_{2} \mathrm{SeO}_{3}$ to ESPS $0.2 \mathrm{~g} / \mathrm{g} ; \mathbf{b}$ fixed conditions: reaction time $5 \mathrm{~h}$, weight ratio of $\mathrm{Na}_{2} \mathrm{SeO}_{3}$ to $\mathrm{ESPS} 0.2 \mathrm{~g} / \mathrm{g}$; c fixed conditions: reaction time $5 \mathrm{~h}$, reaction temperature $80{ }^{\circ} \mathrm{C}$

\section{Results and discussion}

\section{Single-factor assays}

Figure 1a illustrated that Se content of Se-ESPS gradually raised within $3-6 \mathrm{~h}$, but decreased at $7 \mathrm{~h}$. Similarly, the Se content of Se-ESPS rapidly increased in the range of $60-80{ }^{\circ} \mathrm{C}$ while slightly decreased at $90{ }^{\circ} \mathrm{C}$, shown in Fig. 1b. The main reason for the above results was that the excessive reaction time and temperature led to the monosaccharide and oligosaccharide combined with Se were hydrolyzed from ESPS, and were dialyzed out from the solution [32]. Therefore, given saving time and energy, $4-6 \mathrm{~h}$ and $60-80{ }^{\circ} \mathrm{C}$ were selected as levels in
BBD optimization. Figure 1(c) displayed that when the weight ratio of $\mathrm{Na}_{2} \mathrm{SeO}_{3}$ and ESPS reached $1.0 \mathrm{~g} / \mathrm{g}$, the Se content of Se-ESPS slowly increased. The reason was that when the weight ratio of $\mathrm{Na}_{2} \mathrm{SeO}_{3}$ to ESPS reached a certain proportion, the combining rate of $\mathrm{Na}_{2} \mathrm{SeO}_{3}$ and ESPS was saturated, and the increasing $\mathrm{Na}_{2} \mathrm{SeO}_{3}$ could not significantly improve the combining rate [32]. Herein, $0.6-1.0 \mathrm{~g} / \mathrm{g}$ was adopted for the BBD optimization.

\section{Optimized selenization results of Se-ESPS by BBD}

The selenization response surface scheme and results are shown in Table 2. Box-Behnken design provided 17 
Table 2 Selenization schemes by Box-Behnken design and the responsive results

\begin{tabular}{lllll}
\hline No. & \multicolumn{2}{l}{ Factors and levels } & $\begin{array}{l}\text { Se Content of } \\
\text { Se-ESPS }(\mathbf{m g} / \mathbf{g})\end{array}$ \\
\cline { 2 - 4 } & $\mathbf{X}_{\mathbf{1}} \mathbf{( h )}$ & $\mathbf{X}_{\mathbf{2}}\left({ }^{\circ} \mathrm{C}\right)$ & $\mathbf{X}_{\mathbf{3}} \mathbf{( g / g )}$ & \\
\hline 1 & 4 & 70 & 0.8 & 0.793 \\
2 & 6 & 70 & 0.8 & 1.205 \\
3 & 4 & 90 & 0.8 & 0.959 \\
4 & 6 & 90 & 0.8 & 1.592 \\
5 & 4 & 80 & 0.6 & 0.611 \\
6 & 6 & 80 & 0.6 & 1.418 \\
7 & 4 & 80 & 1.0 & 1.755 \\
8 & 6 & 80 & 1.0 & 1.693 \\
9 & 5 & 70 & 0.6 & 0.759 \\
10 & 5 & 90 & 0.6 & 1.286 \\
11 & 5 & 70 & 1.0 & 1.907 \\
12 & 5 & 90 & 1.0 & 2.301 \\
13 & 5 & 80 & 0.8 & 2.974 \\
14 & 5 & 80 & 0.8 & 2.797 \\
15 & 5 & 80 & 0.8 & 2.916 \\
16 & 5 & 80 & 0.8 & 2.865 \\
17 & 5 & 80 & 0.8 & 2.951 \\
\hline
\end{tabular}

experiments, including factorial experiments No. 1-12 and central experiments No. 13-17. The Se content of SeESPS ranged from 0.611 to $2.974 \mathrm{mg} / \mathrm{g}$. Then, the quadratic multinomial regression equation that reflected the relationship between reaction factors and Se content of Se-ESPS was obtained by multiple regression analysis, shown in formula 3.

$$
\begin{aligned}
\mathrm{Y}= & 2.90+0.22 \mathrm{X}_{1}+0.18 \mathrm{X}_{2} \\
& +0.45 \mathrm{X}_{3}+0.055 \mathrm{X}_{1} \mathrm{X}_{2} \\
& -0.22 \mathrm{X}_{1} \mathrm{X}_{3}-0.033 \mathrm{X}_{2} \mathrm{X}_{3} \\
& -0.98 \mathrm{X}_{1}^{2}-0.78 \mathrm{X}_{2}^{2}-0.55 \mathrm{X}_{3}^{2}
\end{aligned}
$$

\section{Model fitting and analysis}

The results of the regression model analysis were shown in Table 3. F value $(74.51)$ and $P$ value $(<0.0001)$ meant that the model owned the high statistical significance. Moreover, $R^{2}$ (0.9879), Adj $R^{2}$ (0.9764), and Adeq precision $(>4)$ indicated the high fitting degree of the model. The low value of C.V.\% (7.16) showed the high accuracy and reliability of the model [33]. F value (6.44) and P value $(0.0817)$ of lack of fit suggested the few variations between the actual and predicted values [34]. All the above illustrated that the model was accurate and reliable. According to the $\mathrm{P}$ values of each model terms, the linear coefficients $\left(\mathrm{X}_{1}, \mathrm{X}_{2}, \mathrm{X}_{3}\right)$, secondary coefficients $\left(\mathrm{X}_{1}^{2}, \mathrm{X}_{2}^{2}, \mathrm{X}_{3}^{2}\right)$, and interactive coefficient $\left(\mathrm{X}_{1} \mathrm{X}_{3}\right)$ significantly influenced selenization $(\mathrm{P}<0.01, \mathrm{P}<0.05)$, while the interaction coefficients $\left(\mathrm{X}_{1} \mathrm{X}_{2}, \mathrm{X}_{2} \mathrm{X}_{3}\right)$ had no significant effect on selenization $(\mathrm{P}>0.05)$.

\section{Interactions of parameters in Se-ESPS}

Figure 2 showed the 3D surface response plots about the interactions of different parameters. In general, if the $2 \mathrm{D}$ contour plot formed by $3 \mathrm{D}$ mapping to the bottom plane is more elliptical, the interaction between the

\begin{tabular}{|c|c|c|c|c|c|c|}
\hline Source & Sum of squares & Df & Mean square & Standard error & F value & P value \\
\hline Model & 11.26 & 9 & 1.25 & - & 74.51 & $<0.0001^{* *}$ \\
\hline$X_{1}$ & 0.40 & 1 & 0.40 & 0.046 & 23.85 & $0.0018^{* *}$ \\
\hline$x_{2}$ & 0.27 & 1 & 0.27 & 0.046 & 16.17 & $0.0050^{* *}$ \\
\hline$x_{3}$ & 1.60 & 1 & 1.60 & 0.046 & 95.52 & $<0.0001^{* *}$ \\
\hline$x_{1} x_{2}$ & 0.012 & 1 & 0.012 & 0.065 & 0.73 & 0.4220 \\
\hline$x_{1} x_{3}$ & 0.19 & 1 & 0.19 & 0.065 & 11.24 & $0.0122^{*}$ \\
\hline$x_{2} x_{3}$ & 4.422E-003 & 1 & $4.422 \mathrm{E}-003$ & 0.065 & 0.26 & 0.6236 \\
\hline$x_{1}^{2}$ & 4.03 & 1 & 4.03 & 0.063 & 240.18 & $<0.0001^{* *}$ \\
\hline$x_{2}^{2}$ & 2.59 & 1 & 2.59 & 0.063 & 154.40 & $<0.0001^{* *}$ \\
\hline$x_{3}^{2}$ & 1.29 & 1 & 1.29 & 0.063 & 76.60 & $<0.0001^{*}$ \\
\hline Residual & 0.12 & 7 & 0.017 & - & - & - \\
\hline Lack of fit & 0.097 & 3 & 0.032 & - & 6.44 & 0.0817 \\
\hline Pure error & 0.020 & 4 & 5.014E-003 & - & - & - \\
\hline Cor total & 11.38 & 16 & - & - & - & - \\
\hline
\end{tabular}
two parameters will be more significant [35]. As Fig. 2a shown, the Se content of Se-ESPS initially increased

Table 3 Variance analysis of optimization of selenization of ESPS

C.V.\% $\%$ 7.16, $R^{2}=0.9897, \operatorname{AdjR}^{2}=0.9764$, Adeq Precision $=24.351$

${ }^{*} \mathrm{P}<0.05 ;{ }^{* *} \mathrm{P}<0.01$ 

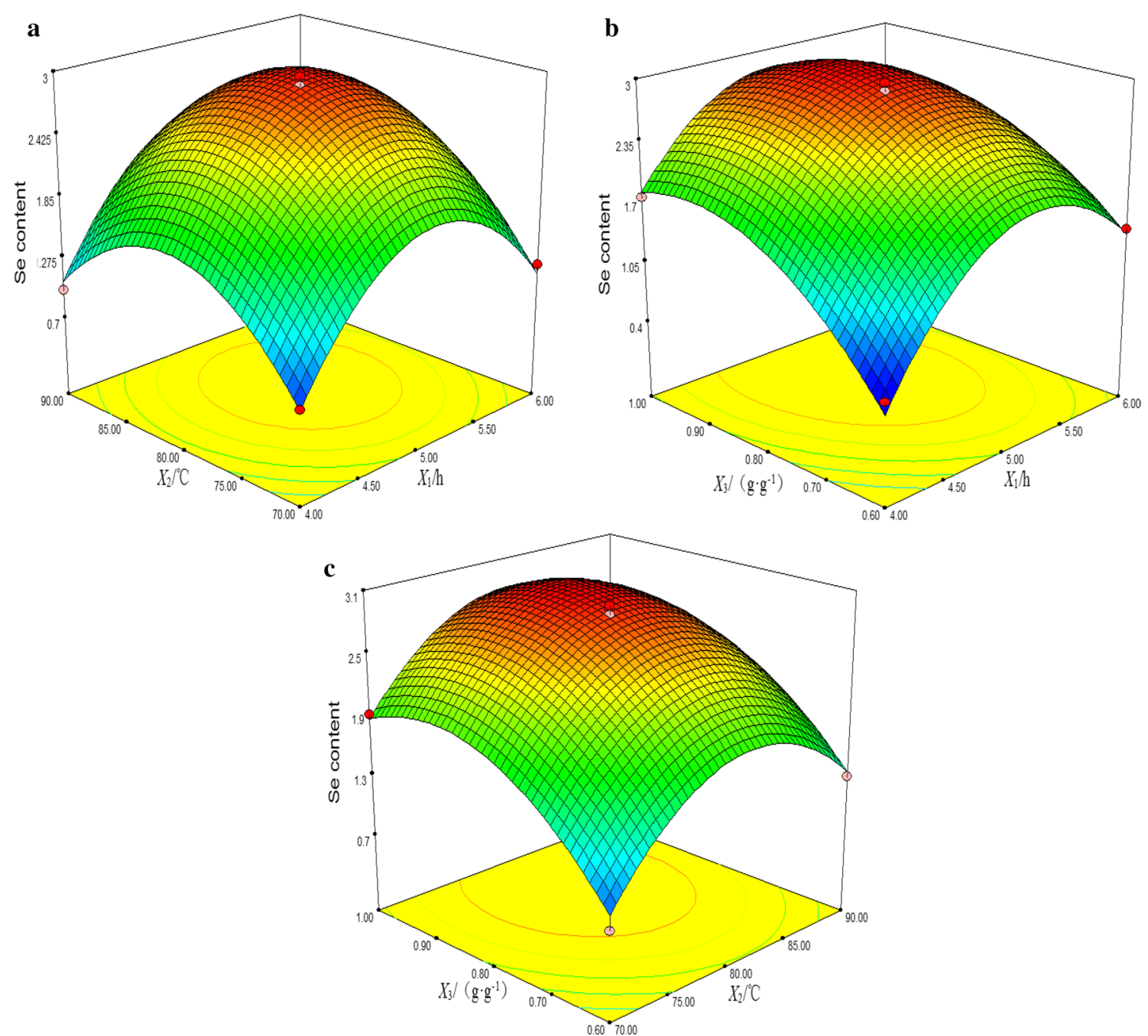

Fig. 2 3D response surface plots about the interactions of different parameters

with reaction time $\left(\mathrm{X}_{1}\right)$ prolongation and reaction temperature $\left(\mathrm{X}_{2}\right)$ increasing, but then decreased. Figure $2 \mathrm{~b}$ revealed that the Se content of Se-ESPS raised with the increase of weight ratio of $\mathrm{Na}_{2} \mathrm{SeO}_{3}$ to ESPS $\left(\mathrm{X}_{3}\right)$, while the content of Se-ESPS presented a trend of rising first and then falling with reaction time $\left(\mathrm{X}_{1}\right)$ prolongation. A similar behavior was also presented in Fig. $2 \mathrm{c}$ about the interaction.

Furthermore, the 2D contour plot of Fig. 2b was elliptical, which meant that the interaction between reaction time $\left(\mathrm{X}_{1}\right)$ and weight ratio of $\mathrm{Na}_{2} \mathrm{SeO}_{3}$ to ESPS $\left(\mathrm{X}_{3}\right)$ was significant $\left(\mathrm{X}_{1} \mathrm{X}_{3}, \mathrm{P}<0.05\right.$, shown in Table 3$)$.

\section{Optimal process and verification experiment}

According to the model, the optimal process of Se-ESPS was obtained: the reaction time, the reaction temperature, the weight ratio of $\mathrm{Na}_{2} \mathrm{SeO}_{3}$ to ESPS was $5.07 \mathrm{~h}$,
$81.11{ }^{\circ} \mathrm{C}, 0.88 \mathrm{~g} / \mathrm{g}$, respectively, and the predicted $\mathrm{Se}$ content in Se-ESPS was $3.006 \mathrm{mg} / \mathrm{g}$. For verifying the accuracy and reliability of the optimal selenization process, the proposed process was corrected as follows: the reaction time was $5 \mathrm{~h}$, the reaction temperature was $81{ }^{\circ} \mathrm{C}$, and the weight ratio of $\mathrm{Na}_{2} \mathrm{SeO}_{3}$ to ESPS was $0.9 \mathrm{~g} / \mathrm{g}$. Based on the corrected process, the Se content of Se-ESPS was $(2.915 \pm 0.03) \mathrm{mg} / \mathrm{g}$. The actual result approached the prediction, which indicated that the SeESPS optimization process was feasible, and the model was accurate and reliable, which could be used for the subsequent selenization experiments. Se-ESPS-B1 was obtained by the optimal process model and the Se content of Se-ESPS-B1 was $3.029 \mathrm{mg} / \mathrm{g}$. 


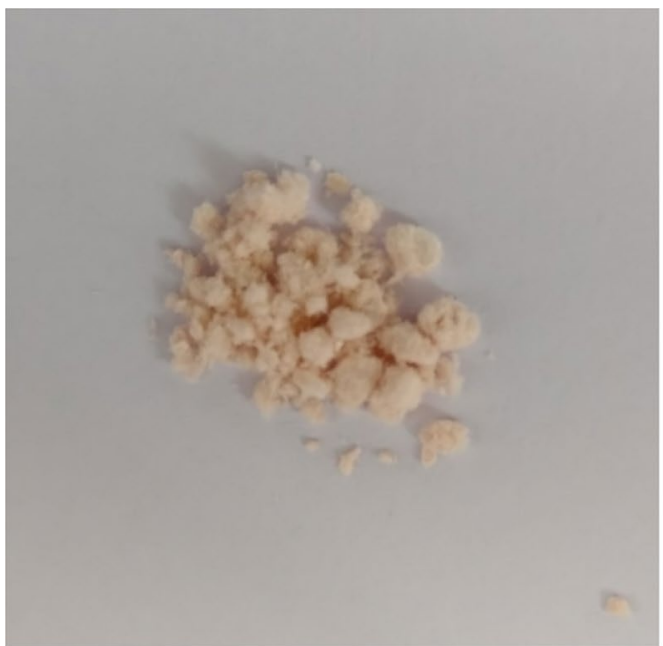

a Se-ESPS-B1

Fig.3 Appearance of Se-ESPS-B1 (a) and ESPS-B1 (b)

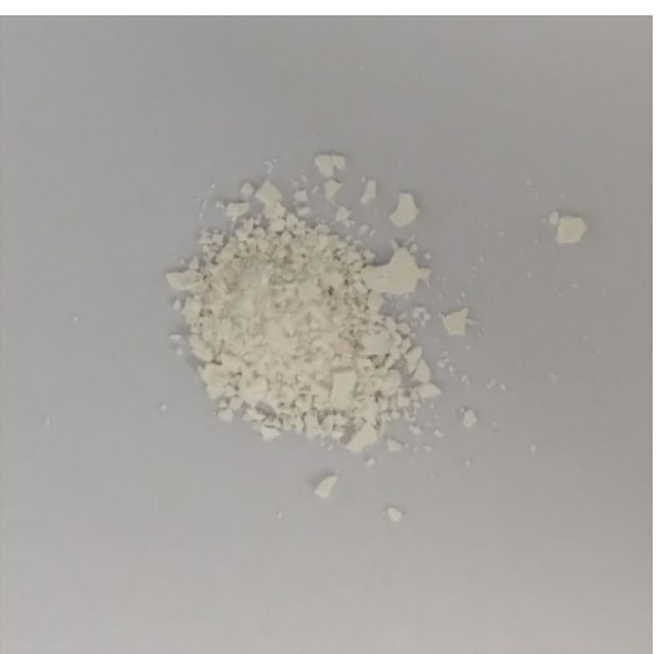

b ESPS-B1

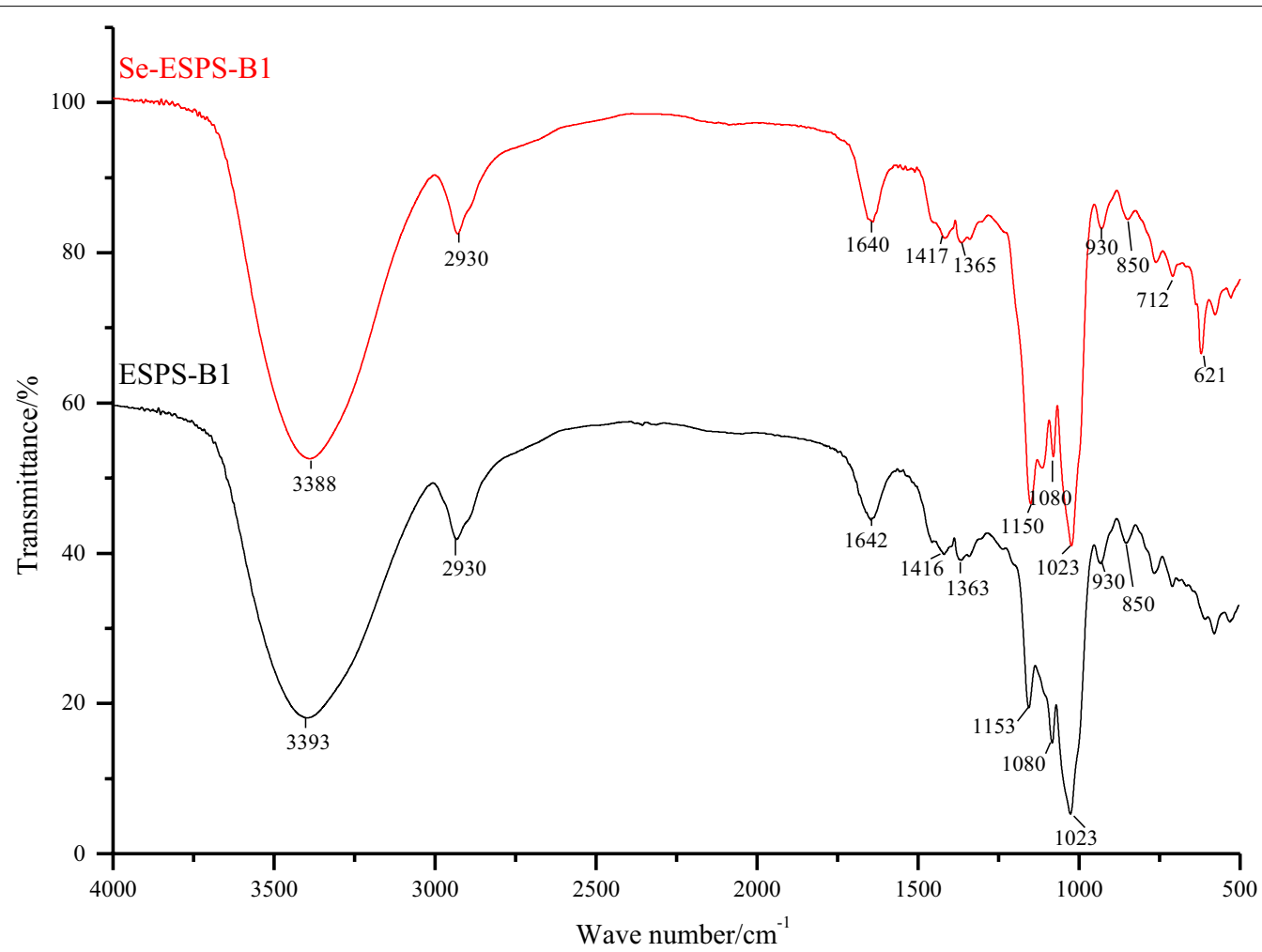

Fig. 4 FTIR spectra of Se-ESPS-B1 and ESPS-B1

\section{Appearance results}

As shown in Fig. 3, Se-ESPS-B1 was pink fluffy floc and ESPS-B1 was a white flake. It implied that the structure of Se-ESPS-B1 had changed to some extent after selenization, compared with ESPS-B1. 


\section{FTIR analysis}

As shown in Fig. 4, both Se-ESPS-B1 and ESPS-B1 had three typical absorption peaks of polysaccharides near 3390, 2930, $1641 \mathrm{~cm}^{-1}$, which were attributed to $\mathrm{O}-\mathrm{H}, \mathrm{C}-\mathrm{H}$ stretching vibration, and $\mathrm{C}=\mathrm{O}$ asymmetric stretching [36], respectively. Two absorption peaks near $1417,1365 \mathrm{~cm}^{-1}$ were attributed to the $\mathrm{C}-\mathrm{H}$ inplane bending vibration of Se-ESPS-B1 and ESPS-B1. The absorption peaks near 1150, 1080, $1023 \mathrm{~cm}^{-1}$ were $\mathrm{C}-\mathrm{O}-\mathrm{C}$ and $\mathrm{C}-\mathrm{O}-\mathrm{H}$ stretching vibrations of polysaccharides with pyran rings, which indicated Se-ESPSB1 and ESPS-B1 were pyran ring polysaccharides. In addition, the absorption peaks near $850 \mathrm{~cm}^{-1}$ and $930 \mathrm{~cm}^{-1}$ were $\alpha$-glycosidic and $\beta$-glycosidic bonds of Se-ESPS-B1 and ESPS-B1 [37]. However, Se-ESPS$\mathrm{B} 1$ had distinctive absorption peaks at $712 \mathrm{~cm}^{-1}$ and $620 \mathrm{~cm}^{-1}$, which were attributed to $\mathrm{Se}=\mathrm{O}$ and $\mathrm{C}-\mathrm{O}-$ Se stretching vibrations [37]. The above result showed that selenium was introduced into ESPS-B1 in the forms with $\mathrm{Se}=\mathrm{O}$ and $\mathrm{C}-\mathrm{O}-\mathrm{Se}$.

\section{Thermogravimetric assays}

It could be seen from Fig. 5 that the TG and DTG curves of Se-ESPS-B1 and ESPS-B1 were similar. Obvious weight loss occurred in the range of $50-100{ }^{\circ} \mathrm{C}$ for Se-ESPS-B1 and ESPS-B1, which was mainly caused by the evaporation of water contained in Se-ESPS-B1 and ESPS-B1, and the weight loss was about 10\% [38].

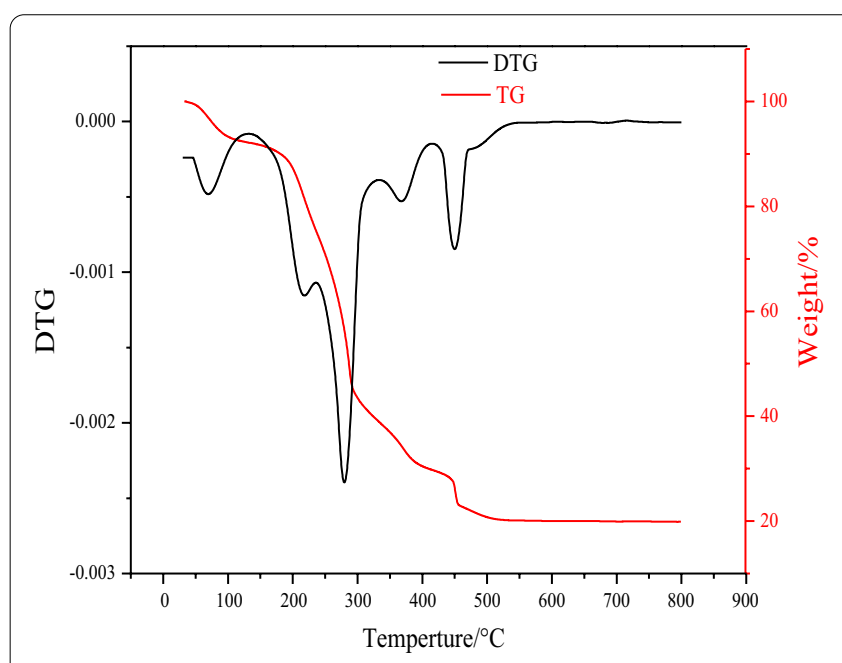

a Se-ESPS-B1

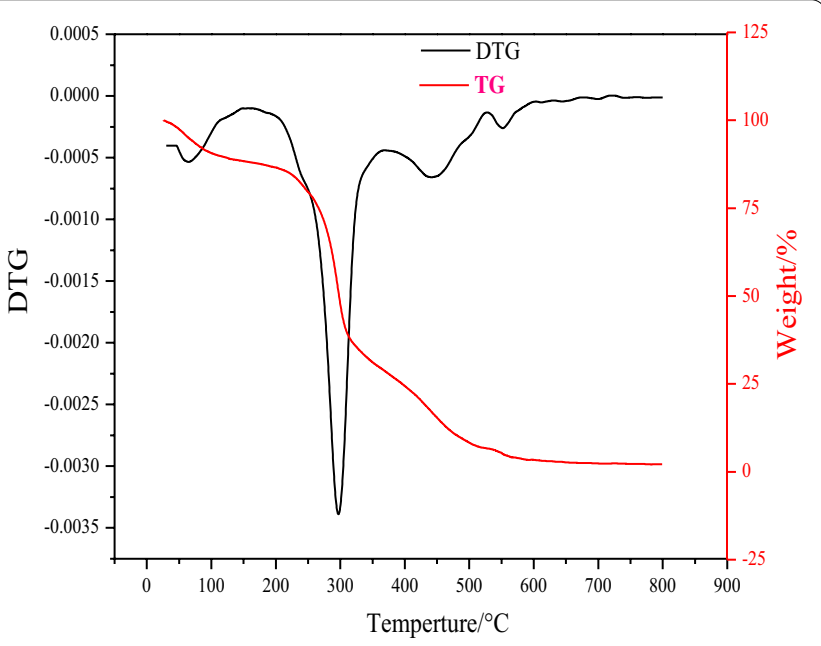

b ESPS-B1

Fig. 5 TG and DTG curves of Se-ESPS-B1 (a) and ESPS-B1 (b)

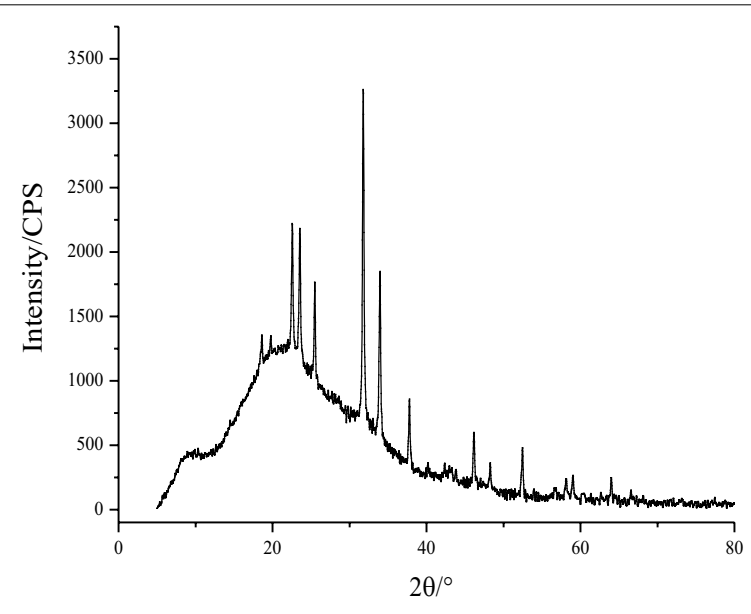

a Se-ESPS-B1

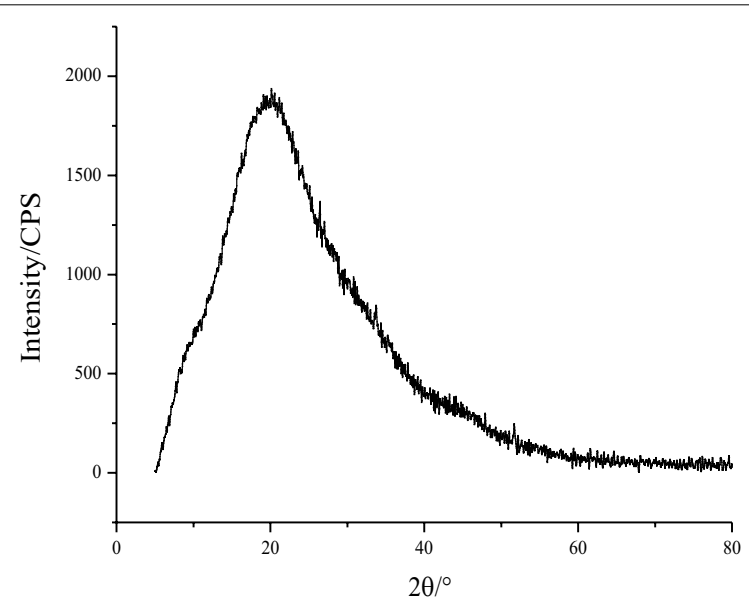

b ESPS-B1

Fig. 6 XRD spectra of Se-ESPS-B1 (a) and ESPS-B1 (b) 
Figure 5a showed that the weight loss rate of Se-ESPSB1 increased rapidly with the gradual increase of temperature. The maximum weight loss was in the range of $200-350{ }^{\circ} \mathrm{C}$, and the weight loss was about $65 \%$. In particular, the weight loss was most severe at $278{ }^{\circ} \mathrm{C}$, indicating that Se-ESPS-B1 was violently decomposed within this range. Similarly, ESPS-B1 decomposed violently in the range of $250-370{ }^{\circ} \mathrm{C}$, especially at $297{ }^{\circ} \mathrm{C}$, and the weight loss rate of ESPS-B1 was about $60 \%$, shown in Fig. 5b. From the above analysis, it could be concluded that the thermal stability of Se-ESPS-B1was lower than that of ESPS-B1.

\section{X-ray diffraction assays}

As shown in Fig. 6, Se-ESPS-B1 owned obvious diffraction peaks in the range of $20^{\circ}-40^{\circ}$, indicating that it has the crystal structure, while ESPS- B1 has no diffraction peak in that range, indicating that ESPS-B1 was amorphous [39]. It was suggested that the structure of Se-ESPS-B1 significantly changed after selenization, compared with that of Se-ESPS-B1.

\section{X-ray photoelectron spectroscopy assays}

From the X-ray photoelectron spectra of Se-ESPS-B1 and ESPS-B1 in Fig. 7, it could be seen that both of them have
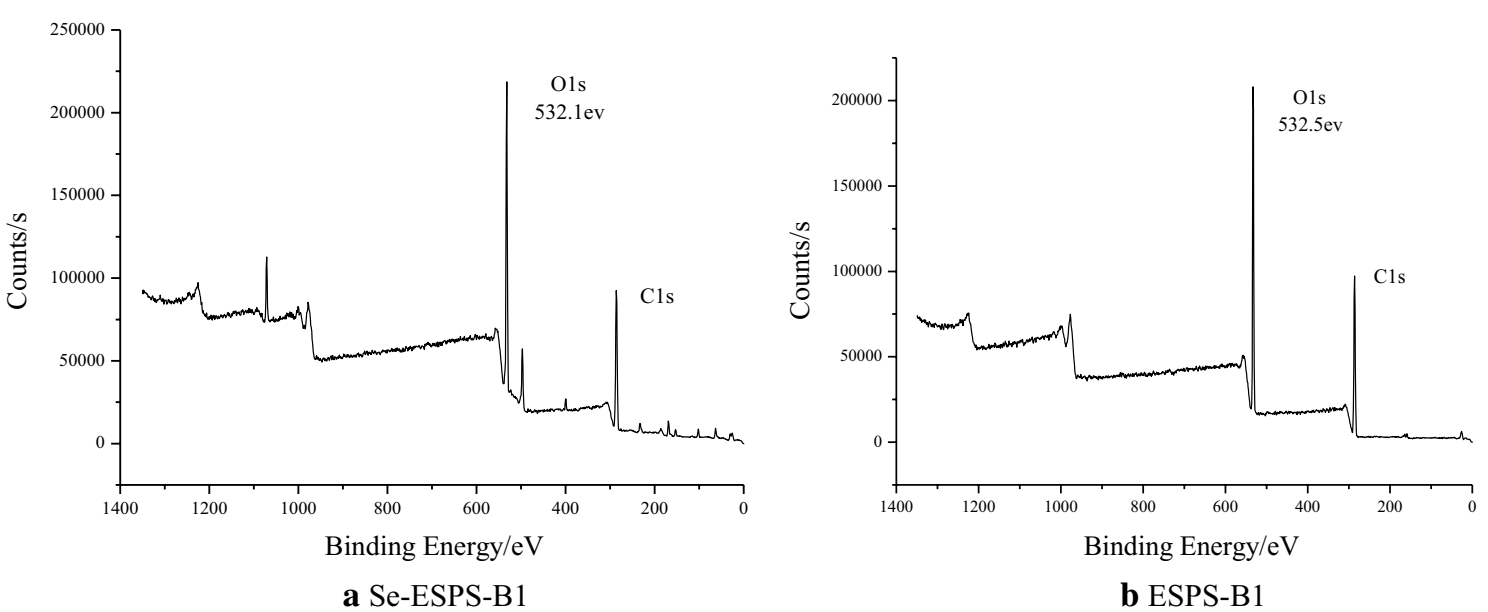

Fig. 7 XPS spectra of Se-ESPS-B1 (a) and ESPS-B1 (b)
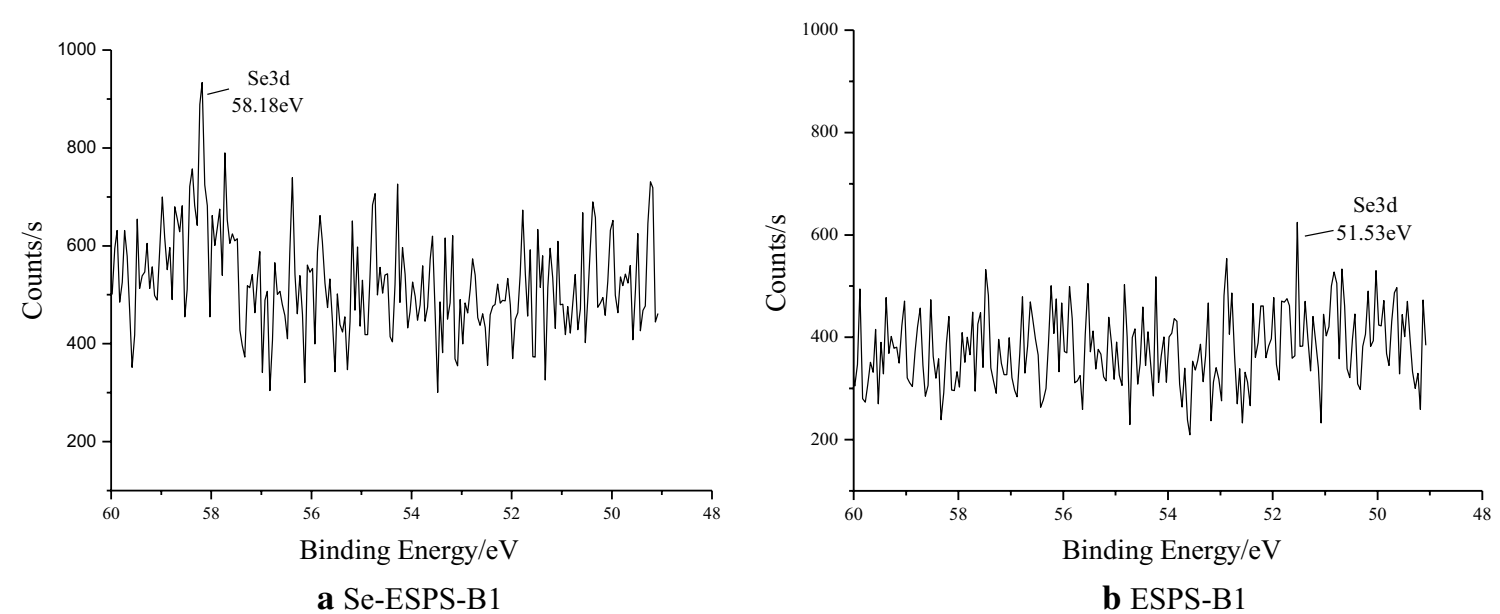

Fig. 8 Se3d core level spectra of Se-ESPS-B1 (a) and ESPS-B1 (b) 
significant $\mathrm{C} 1 \mathrm{~s}$ and $\mathrm{O} 1 \mathrm{~s}$ peaks, indicating that the main components of the tested substance were $\mathrm{C}, \mathrm{O}$, and $\mathrm{H}$. According to the elemental composition, the main components were inferred carbohydrates. Furthermore, the O1s binding energy of Se-ESPS-B1 $(532.1 \mathrm{eV})$ was lower than that of ESPS-B1 $(532.5 \mathrm{eV})$, which indicated that the introduction of selenium caused the change of electron cloud density of $\mathrm{O}$ atom in the polysaccharide. When $\mathrm{Se}=\mathrm{O}$ replaced the hydroxyl hydrogen on the half-acetal oxygen ring, Se atom contributed electrons to increase the density of the electron cloud on the half-acetal oxygen ring. Further, the density of oxygen electron cloud on half-acetal oxygen ring increased and reduced the binding force of $\mathrm{O}$ atom to bind the remaining electrons in the orbital, resulting in the decrease of the binding energy [40].

Besides, the above conclusion could be verified by the Se3d spectra of Se-ESPS-B1 and ESPS-B1. Figure 8 showed that the Se3d peak of Se-ESPS-B1 was much higher than that of ESPS-B1, which indicated that more Se was introduced into the polysaccharide molecules, and the Se3d binding energy of Se-ESPS-B1was $58.18 \mathrm{eV}$, while that of ESPS-B1 was $51.53 \mathrm{eV}$. The results showed that $\mathrm{Se}$ atoms provided outer electrons to $\mathrm{O}$ atoms after entering into the internal molecular structure of polysaccharides, which reduced the binding energy of O1s and increased the binding energy of Se3d. Therefore, it could be speculated that Se formed a chemical bond with the $\mathrm{O}$ atom in the polysaccharide molecule. It was consistent with the result of FTIR spectra.

Moreover, the results of XPS could effectively explain the conclusion that the thermal stability of Se-ESPS-B1 was worse than that of ESPS-B1: When Se atoms were introduced into ESPS-B1 molecular chain structure in the form of $\mathrm{HSeO}_{3}{ }^{-}$, it had the strong electron supply ability, which reduced $\mathrm{C}-\mathrm{O}$ bonding energy in Se-ESPSB1 molecule chains and C-O bond in Se-ESPS-B1 could be easily broken, causing Se-ESPS-B1 decomposed earlier than ESPS-B1 in the thermogravimetric analysis.

\section{SEM image results}

Figure 9 showed the SEM images of Se-ESPS-B1 and ESPS-B1 at different magnifications. Under the low magnifications, Se-ESPS-B1 presented flocculent particles. From the magnification of 60,000 , it could be seen that the microscopic morphology of Se-ESPS-B1 was the small and dense branch-like structure. The branches were multi-bifurcated, quasi-circular, and quasi-spherical, and the surface is smooth and non-porous. The morphology of Se-ESPS-B1 was similar to that of microcrystalline [38, 41]. Meanwhile, the microscopic morphology of ESPSB1 was sheet-like and rod-shaped, with a smooth surface and no bifurcation, which suggested that the interaction between ESPS-B1 molecules was strong and the binding was tight. In addition to the Se-O bond and C-O-Se bond between selenium and polysaccharides, the difference in microscopic morphology between Se-ESPS-B1 and ESPS-B1 may be due to the changes of internal hydrogen bond and intermolecular van der Waals force caused by the introduction of selenium $[42,43]$.

\section{Antioxidant activity assays of Se-ESPS-B1}

DPPH scavenging method is widely used for quantitative evaluation of free radical scavenging capacity of bioactive substances because of its simplicity and sensitivity. As shown in Fig. 10a, when Se-ESPS-B1 concentration was $0.2 \mathrm{mg} / \mathrm{mL}$, the DPPH scavenging rate was $60.5 \%$. After that, the DPPH radical scavenging rate gradually raised with the increase of Se-ESPS-B1 concentration and reached $89.7 \%$ at the Se-ESPS-B1 concentration of $1.0 \mathrm{mg} / \mathrm{mL}$. It could also be seen that Se-ESPS-B1 could significantly scavenge DPPH radical, compared with that of ESPS-B1.

ABTS scavenging method is another effective approach to detect the free radical scavenging ability of potential antioxidants. It could be seen observed from Fig. 10b that ABTS radical scavenging rate raised with the increase of Se-ESPS-B1 and ESPS-B1 concentrations. The highest ABTS radical scavenging rate of Se-ESPS-B1 reached $85.2 \%$. Moreover, the ABTS radical scavenging ability of Se-ESPS-B1 was significantly higher than that of ESPS-B1.

. OH scavenging method is of great significance for revealing active ingredients in treating certain diseases and delaying aging. Figure $10 \mathrm{c}$ indicated that $\cdot \mathrm{OH}$ radical scavenging rate was positively correlated with SeESPS-B1 concentrations. When the concentration of Se-ESPS-B1 was $0.2 \mathrm{mg} / \mathrm{mL}$, the $\cdot \mathrm{OH}$ radical scavenging rate was low, but when the concentration exceeds $0.4 \mathrm{mg} / \mathrm{ml}$, the $\cdot \mathrm{OH}$ radical scavenging rate was significantly improved. At $1.0 \mathrm{mg} / \mathrm{mL}$, the $\cdot \mathrm{OH}$ radical scavenging rate reached $79.9 \%$. Similarly, the $\cdot \mathrm{OH}$ radical scavenging rate of Se-ESPS-B1 was higher than that of ESPS-B1.

In general, the stronger the reduction ability implies the stronger the antioxidant activity. Figure $10 \mathrm{~d}$ displayed that the reduction abilities of Se-ESPS-B1 and ESPS-B1 increased with the increase of concentration, showing a dose-dependent relationship. At the same dose, the reduction ability of Se-ESPS-B1is significantly higher than that of ESPS-B1. When the concentration of Se-ESPS-B1 was $1.0 \mathrm{mg} / \mathrm{mL}$, the maximum reduction capacity was 0.54 .

Similar to the above results, many studies have demonstrated that selenium-polysaccharide exhibits the 


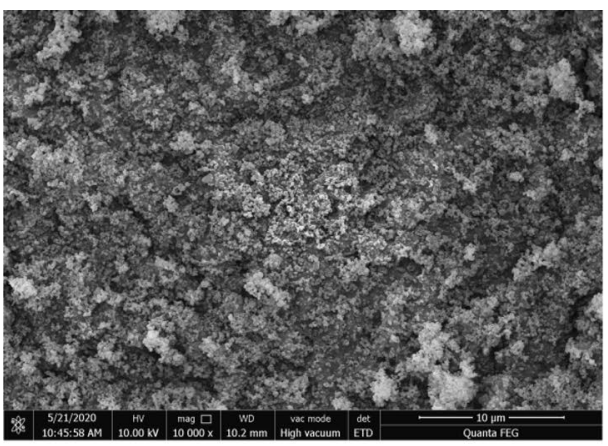

$10000 \times$

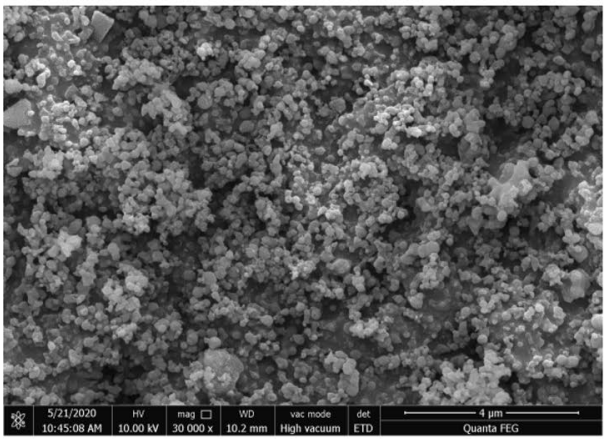

$30000 \times$

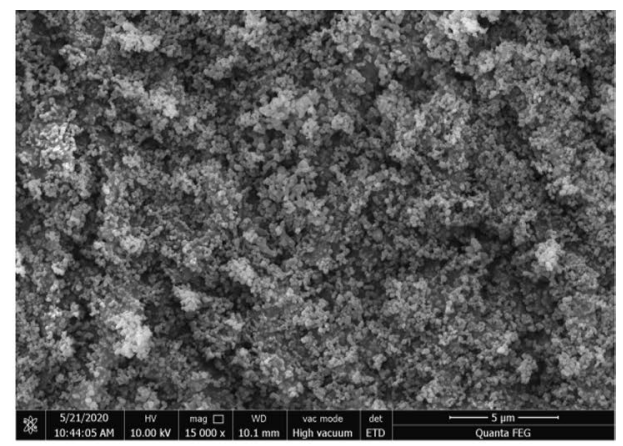

$15000 \times$

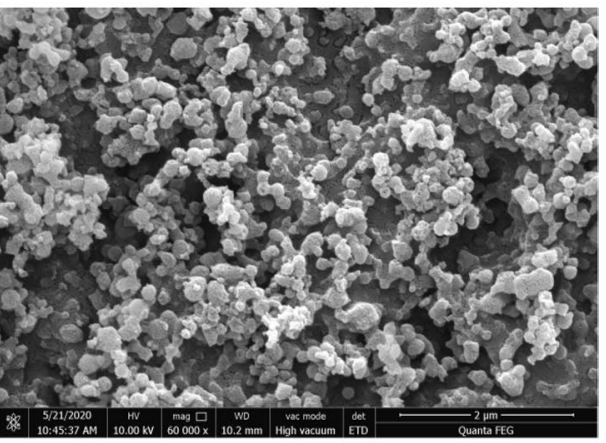

$60000 \times$

a Se-ESPS-B1

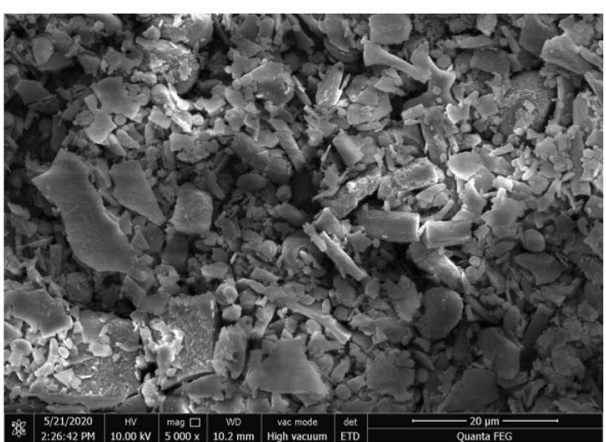

$5000 \times$

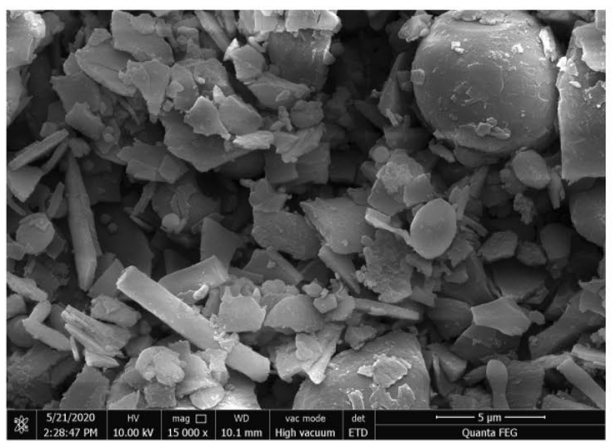

$15000 \times$

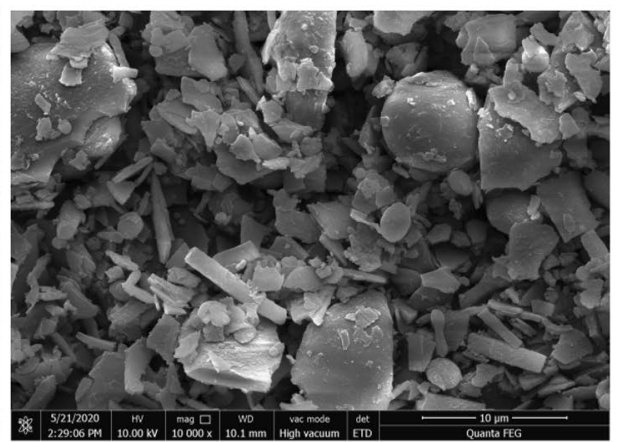

$10000 \times$

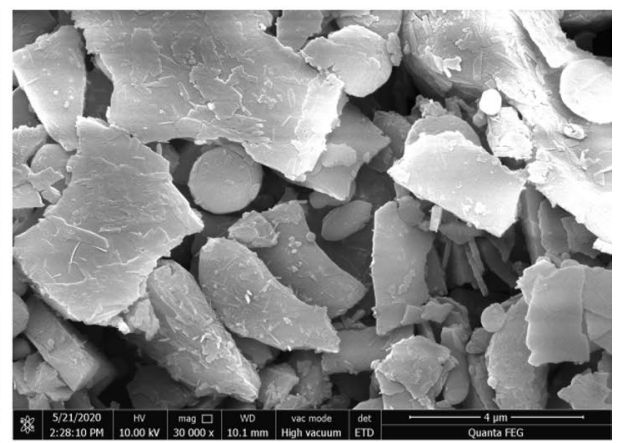

$30000 \times$

b ESPS-B1

Fig. 9 SEM micrographs of Se-ESPS-B1 (a) and ESPS-B1 (b) under the different magnifications 

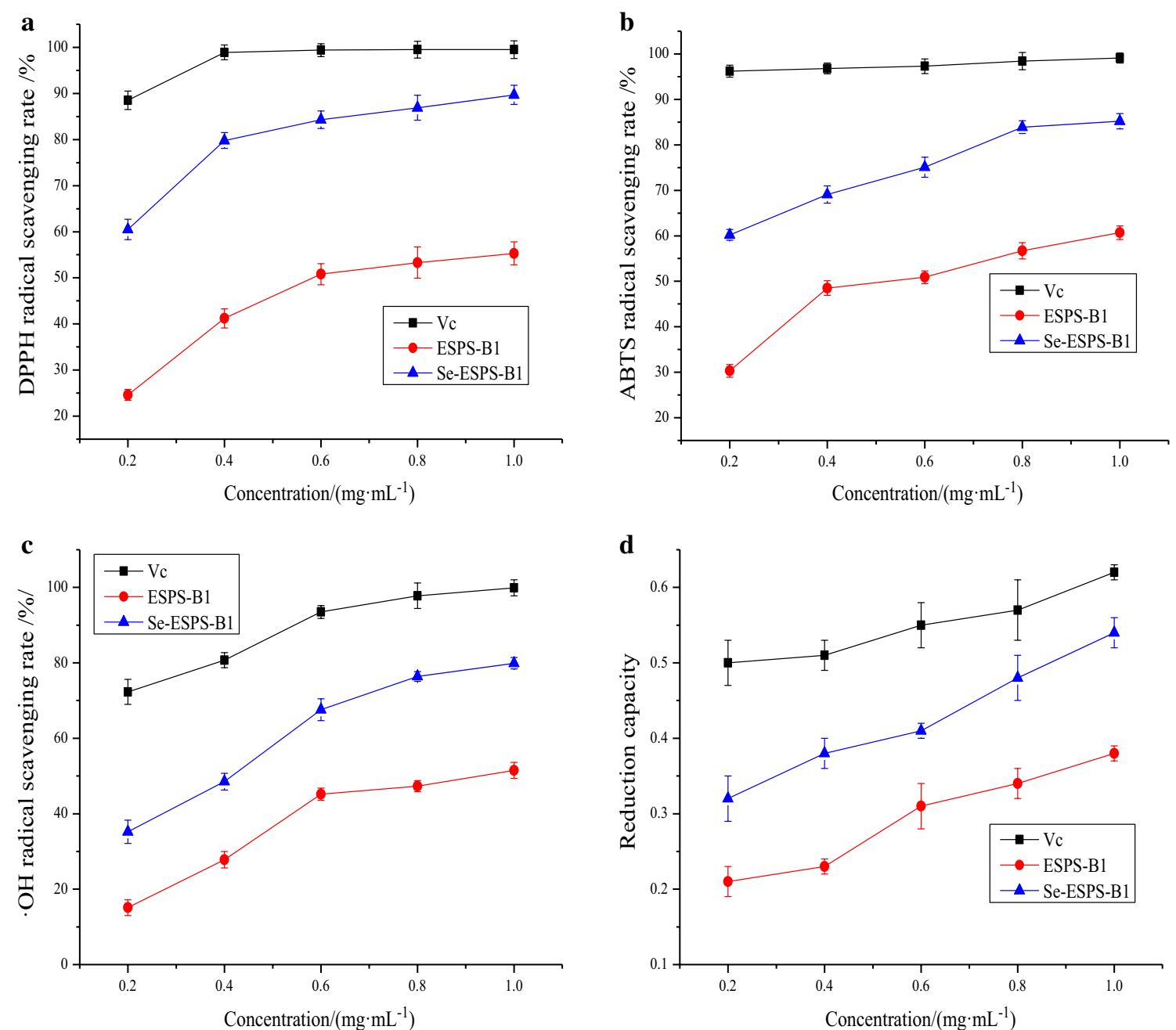

Fig.10 The levels of DPPH radical scavenging $(\mathbf{a})$, ABTS radical scavenging $(\mathbf{b})$, $\cdot$ OH radical scavenging $(\mathbf{c})$, and reduction ability $(\mathbf{d})$ of Se-ESPS-B1 and ESPS-B1

antioxidant activity in vitro [44-47]. The possible chemical mechanisms for the antioxidant activity were shown as follows: firstly, the hydroxyl groups in SeESPS-B1 and ESPS-B1 were reacted with ferric iron, which reduced the production of free radicals induced by ferric iron [48]. Secondly, selenium in Se-ESPS-B1 could also directly trap the electrophilic free radicals [49]. Besides, compared with ESPS-B1, Se-ESPS-B1 showed significant antioxidant activity in vitro. It could also be concluded from the above results that Se-ESPSB1 after selenization has the dual antioxidant activities of polysaccharide and selenium.

\section{Abbreviations}

ESPS: Euryale ferox Salisb. polysaccharide; Se-ESPS: Selenium-Euryale ferox Salisb. polysaccharide.

\section{Acknowledgements}

Not applicable.

\section{Authors' contributions}

FD and $\mathrm{ZHZ}$ designed the experiment, analyzed the data and wrote the original draft. WSJ and SKC analyzed the results and checked the manuscript. $Z Y Q$ and $X Z$ detected the characterzation. CL detected the antioxidant activity in vitro. QX implemented response surface design. FF supervised and guided the experiment and writing process. All authors read and approved the final manuscript.

\section{Funding}

This work was supported by the Natural Science Foundation of Huai'an, Jiangsu Provence (HAB201840), the National Natural Science Foundation of China (82003701), the Major Science and Technology Demonstration Projects of Jiangsu Province, China (BE2018678-3), Cyan Engineering Grant Program of Jiangsu Province for Key Teacher in University (2018[12]) and Foundation 
of Food and Drug Research Institute of Jiangsu Food and Pharmaceutical Science College (6011900105).

\section{Availability of data and materials}

The data presented in this paper are available on request from the first author and corresponding author.

\section{Declarations}

\section{Competing interests}

The authors declare no competing interests.

\section{Author details}

'School of Health Sciences, Jiangsu Food and Pharmaceutical Science College, Huai'an 223003, China. ${ }^{2}$ School of Pharmacy, Harbin University of Commerce, Harbin 150076, China. ${ }^{3}$ School of Food Science and Biotechnology, Kyungpook National University, Daegu 41566, Republic of Korea. ${ }^{4}$ School of Life Sciences, University of Sussex, Brighton BN19RH, UK. ${ }^{5}$ School of Life Science and Technology, China Pharmaceutical University, Nanjing 211198, China.

Received: 7 May 2021 Accepted: 8 August 2021

Published online: 14 August 2021

\section{References}

1. Dorszewska J, Kowalska M, Prendecki M, Piekut T, Kozłowska J, Kozubski W (2021) Oxidative stress factors in Parkinson's disease. Neural Regen Res 16(7):1383-1391

2. Keuters MH, Keksa-Goldsteine V, Dhungana H, Huuskonen MT, Pomeshchik Y, Savchenko E, Korhonen PK, Singh Y, Wojciechowski S, Lehtonen Š, Kanninen KM, Malm T, Sirviö J, Muona A, Koistinaho M, Goldsteins G, Koistinaho J (2021) An arylthiazyne derivative is a potent inhibitor of lipid peroxidation and ferroptosis providing neuroprotection in vitro and in vivo. Sci Rep 11(1):3518

3. Mangiapane E, Pessione A, Pessione E (2014) Selenium and selenoproteins: an overview on different biological systems. Curr Protein Pept Sci 15(6):598-607

4. Liu L, Wu C, Chen D, Yu B, Huang Z, Luo Y, Zheng P, Mao X, Yu J, Luo J, Yan $\mathrm{H}, \mathrm{He} J(2020)$ Selenium-enriched yeast alleviates oxidative stress-induced intestinal mucosa disruption in weaned pigs. Oxid Med Cell Longev 2020:5490743

5. Xu HB, Zhang LP, Fan HH, Sun J, Wang XW, Hu SZ (1989) A study on the interaction between selenium compounds and lipid peroxy radical. Acta Chim Sinica 47(9):901-906

6. Barbosa NV, Nogueira CW, Nogara PA, de Bem AF, Aschner M, Rocha JBT (2017) Organoselenium compounds as mimics of selenoproteins and thiol modifier agents. Metallomics 9(12):1703-1734

7. Qazi IH, Angel C, Yang H, Pan B, Zoidis E, Zeng CJ, Han H, Zhou GB (2018) Selenium, selenoproteins, and female reproduction: a review. Molecules 23(12):3053

8. Ren X, Zou L, Lu J, Holmgren A (2018) Selenocysteine in mammalian thioredoxin reductase and application of ebselen as a therapeutic. Free Radic Biol Med 127:238-247

9. Busker S, Page B, Arnér ESJ (2020) To inhibit TrxR1 is to inactivate STAT3Inhibition of TrXR1 enzymatic function by STAT3 small molecule inhibitors. Redox Biol 36:101646

10. Jovanović M, Zhukovsky D, Podolski-Renić A, Žalubovskis R, Dar'in D, Sharoyko V, Tennikova T, Pešić M, Krasavin M (2020) Further exploration of DVD-445 as a lead thioredoxin reductase (TrxR) inhibitor for cancer therapy: optimization of potency and evaluation of anticancer potential. Eur J Med Chem 191:112119

11. Wang J, Zhao S, Yang L, Gong H, Li H, Nima C (2020) Assessing the health Loss from Kashin-Beck disease and its relationship with environmental selenium in Qamdo district of Tibet, China. Int J Environ Res Public Health 18(1):11

12. Wang S, Yan R, Wang B, Meng P, Tan W, Guo X (2019) The functional analysis of selenium-related genes and magnesium-related genes in the gene expression profile microarray in the peripheral blood mononuclear cells of Keshan disease. Biol Trace Elem Res 192(1):3-9
13. Kiełczykowska M, Kocot J, Paździor M, Musik I (2018) Selenium-a fascinating antioxidant of protective properties. Adv Clin Exp Med 27(2):245-255

14. Ahmed D, Khan Ml, Sharma M, Khan MF (2018) Novel pentacyclic triterpene isolated from seeds of Euryale Ferox Salisb. ameliorates diabetes in streptozotocin induced diabetic rats. Interdiscip Toxicol 11(4):275-288

15. Zhang WN, Su RN, Gong LL, Yang WW, Chen J, Wang YRY, Pan WJ, Lu YM, Chen Y (2019) Structural characterization and in vitro hypoglycemic activity of a glucan from Euryale ferox Salisb. seeds. Carbohydr Polym 209:363-371

16. Wu CY, Wang H, He XX, Wu DW, Yue W, Wu QN (2017) The hypoglycemic and antioxidant effects of polysaccharides from the petioles and pedicels of Euryale ferox Salisb. on alloxan-induced hyperglycemic mice. Food Funct 8(10):3803-3813

17. Huang S, Yang W, Huang G (2020) Preparation and activities of selenium polysaccharide from plant such as Grifola frondosa. Carbohydr Polym 242:116409

18. Wang J, Yang X, Bao A, Liu X, Zeng J, Liu X, Yao J, Zhang J, Lei Z (2017) Microwave-assisted synthesis, structure and anti-tumor activity of selenized Artemisia sphaerocephala polysaccharide. Int J Biol Macromol 95:1108-1118

19. Yang W, Huang G, Huang H (2020) Preparation and structure of polysaccharide selenide. Ind Crops Prod 154:112630

20. Hamid M, Liu D, Abdulrahim Y, Khan A, Qian G, Huang K (2017) Inactivation of kupffer cells by selenizing Astragalus polysaccharides prevents $\mathrm{CCl}_{4}$-induced hepatocellular necrosis in the male wistar rat. Biol Trace Elem Res 179(2):226-236

21. Gao P, Bian J, Xu S, Liu C, Sun Y, Zhang G, Li D, Liu X (2020) Structural features, selenization modification, antioxidant and anti-tumor effects of polysaccharides from alfalfa roots. Int J Biol Macromol 149:207-214

22. Zhu S, Hu J, Liu S, Guo S, Jia Y, Li M, Kong W, Liang J, Zhang J, Wang J (2020) Synthesis of Se-polysaccharide mediated by selenium oxychloride: structure features and antiproliferative activity. Carbohydr Polym 246:116545

23. Liu X, Xu S, Ding X, Yue D, Bian J, Zhang X, Zhang G, Gao P (2020) Structural characteristics of Medicago Sativa L. polysaccharides and Semodified polysaccharides as well as their antioxidant and neuroprotective activities. Int J Biol Macromol 147:1099-1106

24. Cao L, Yu M, Wang C, Bao Y, Zhang M, He P, Zhang Y, Yang T, Li L, Li G, Gong Y (2019) Cellulase-assisted extraction, characterization, and bioactivity against rheumatoid arthritis of Astragalus polysaccharides. Int J Polym Sci 2019:8514247

25. Almajed A, Srirama D, Moghal AAB (2021) Response surface method analysis of chemically stabilized fiber-reinforced soil. Materials 14(16):1535

26. Hadidi M, Amoli PI, Jelyani AZ, Hasiri Z, Rouhafza A, Ibarz A, Khaksar FB, Tabrizi ST (2020) Polysaccharides from pineapple core as a canning by-product: extraction optimization, chemical structure, antioxidant and functional properties. Int J Biol Macromol 163:2357-2364

27. Kazemi M, Khodaiyan F, Hosseini SS (2019) Eggplant peel as a high potential source of high methylated pectin: ultrasonic extraction optimization and characterization. LWT 105:182-189

28. Lian KX, Zhu XQ, Chen J, Liu G, Gu XL (2018) Selenylation modification: enhancement of the antioxidant activity of a Glycyrrhiza uralensis polysaccharide. Glycoconj J 35(2):243-253

29. Bouabid K, Lamchouri F, Toufik H, Faouzi MEA (2020) Phytochemical investigation, in vitro and in vivo antioxidant properties of aqueous and organic extracts of toxic plant: Atractylis gummifera L. J Ethnopharmacol 253:112640

30. Zhu M, Huang Y, Wang Y, Shi T, Zhang L, Chen Y XM (2019) Comparison of (poly) phenolic compounds and antioxidant properties of pomace extracts from kiwi and grape juice. Food Chem 271:425-432

31. Vasyliev GS, Vorobyova VI, Linyucheva OV (2020) Evaluation of reducing ability and antioxidant activity of fruit pomace extracts by spectrophotometric and electrochemical methods. J Anal Methods Chem 2020:8869436

32. Ji YB, Dong F, Yu M, Qin L, Liu D (2013) Optimization of synthesis of seleno-Sargassum fusiforme (Harv.) Setch. polysaccharide by response surface methodology, its characterization, and antioxidant activity. J Chem 2013:493524

33. Wang B, Xu Y, Chen L, Zhao G, Mi Z, Lv D, Niu J (2020) Optimizing the extraction of polysaccharides from Bletilla ochracea Schltr. using response 
surface methodology (RSM) and evaluating their antioxidant activity. Processes 8(3):341

34. Ahmad A, Rehman MU, Wali AF, El-Serehy HA, Al-Misned FA, Maodaa SN, Aljawdah HM, Ahmad MTMP (2020) Box-Behnken response surface design of polysaccharide extraction from Rhododendron arboretum and the evaluation of its antioxidant potential. Molecules 25(17):3835

35. Wang $Y$, Wang $X$, Xiong $Y$, Fan J, Zheng Z, Li Y, Dong L, Zhao Z (2019) Extraction optimization, separation and antioxidant activity of Luffa cylindrica polysaccharides. Food Bioprod Process 116:98-104

36. Zhou N, Long H, Wang C, Zhu Z, Yu L, Yang W, Ren X, Liu X (2020) Characterization of selenium-containing polysaccharide from Spirulina platensis and its protective role against Cd-induced toxicity. Int J Biol Macromol 164:2465-2476

37. Zhang Y, Zhang Z, Liu H, Wang D, Wang J, Deng Z, Li T, He Y, Yang Y, Zhong S (2020) Physicochemical characterization and antitumor activity in vitro of a selenium polysaccharide from Pleurotus ostreatus. Int J Biol Macromol 165:2934-2946

38. Wang L, Li C, Huang Q, Fu X (2019) Biofunctionalization of selenium nanoparticles with a polysaccharide from Rosa roxburghii fruit and their protective effect against $\mathrm{H}_{2} \mathrm{O}_{2}$-induced apoptosis in INS-1 cells. Food Funct 10(2):539-553

39. Cai W, Hu T, Bakry AM, Zheng Z, Xiao Y, Huang Q (2018) Effect of ultrasound on size, morphology, stability and antioxidant activity of selenium nanoparticles dispersed by a hyperbranched polysaccharide from Lignosus rhinocerotis. Ultrason Sonochem 42:823-831

40. Wei Y, Zhao Q, Wu Q, Zhang H, Kong W, Liang J, Yao J, Zhang J, Wang J (2019) Efficient synthesis of polysaccharide with high selenium content mediated by imidazole-based acidic ionic liquids. Carbohydr Polym 203:157-166

41. Gu Y, Qiu Y, Wei X, Li Z, Hu Z, Gu Y, Zhao Y, Wang Y, Yue T, Yuan Y (2020) Characterization of selenium-containing polysaccharides isolated from selenium-enriched tea and its bioactivities. Food Chem 316:126371
42. Mobika J, Rajkumar M, Sibi LSP, Priya NV (2021) Investigation on hydrogen bonds and conformational changes in protein/polysaccharide/ceramic based tri-component system. Spectrochim Acta A Mol Biomol Spectrosc 5(244):118836

43. Yang YL, Guo SJ, Zhang ZX, Zhang Y, Liu A, Xie LL, Zheng YZ (2018) Structural elucidation of galactomannan from seeds of Crotalaria mucronata Desv. by atomic force microscopy. Mol Med Rep 17(3):3870-3876

44. Jalali S, Montazer M, Rad MM (2021) Biologically active PET/polysaccharide-based nanofibers post-treated with selenium/tragacanth gum nanobiocomposites. Carbohydr Polym 251:117125

45. Ma L, Zhao Y, Yu J, Ji H, Liu A (2018) Characterization of Se-enriched Pleurotus ostreatus polysaccharides and their antioxidant effects in vitro. Int J Biol Macromol 111:421-429

46. Zhao B, Zhang J, Yao J, Song S, Yin Z, Gao Q (2013) Selenylation modification can enhance antioxidant activity of Potentilla anserina $\mathrm{L}$. polysaccharide. Int J Biol Macromol 58:320-328

47. Liu X, Gao Y, Li D, Liu C, Jin M, Bian J, Lv M, Sun Y, Zhang L, Gao P (2018) The neuroprotective and antioxidant profiles of selenium-containing polysaccharides from the fruit of Rosa laevigata. Food Funct 9(3):1800-1808

48. Zhou N, Long H, Wang C, Yu L, Zhao M, Liu X (2020) Research progress on the biological activities of selenium polysaccharides. Food Funct 11(6):4834-4852

49. Kora AJ (2018) Tree gum stabilised selenium nanoparticles: characterisation and antioxidant activity. IET Nanobiotechnol 12(5):658-662

\section{Publisher's Note}

Springer Nature remains neutral with regard to jurisdictional claims in published maps and institutional affiliations.

\section{Submit your manuscript to a SpringerOpen ${ }^{\circ}$ journal and benefit from:}

- Convenient online submission

- Rigorous peer review

- Open access: articles freely available online

- High visibility within the field

- Retaining the copyright to your article

Submit your next manuscript at $\boldsymbol{\nabla}$ springeropen.com 